\title{
Reduction of Escherichia coli, Salmonella Enteritidis and Campylobacter jejuni in poultry manure by rearing of Musca domestica fly larvae
}

\author{
Nordentoft, Steen; Fischer, C.; Bjerrum, L.; Heckmann, L. H. ; Hald, Birthe
}

Published in:

Journal of Insects as Food and Feed

Link to article, DOI:

10.3920/JIFF2016.0058

Publication date:

2017

Document Version

Publisher's PDF, also known as Version of record

Link back to DTU Orbit

Citation (APA):

Nordentoft, S., Fischer, C., Bjerrum, L., Heckmann, L. H., \& Hald, B. (2017). Reduction of Escherichia coli, Salmonella Enteritidis and Campylobacter jejuni in poultry manure by rearing of Musca domestica fly larvae. Journal of Insects as Food and Feed, 3(2), 145-153. https://doi.org/10.3920/JIFF2016.0058

\section{General rights}

Copyright and moral rights for the publications made accessible in the public portal are retained by the authors and/or other copyright owners and it is a condition of accessing publications that users recognise and abide by the legal requirements associated with these rights.

- Users may download and print one copy of any publication from the public portal for the purpose of private study or research.

- You may not further distribute the material or use it for any profit-making activity or commercial gain

- You may freely distribute the URL identifying the publication in the public portal 


\title{
Reduction of Escherichia coli, Salmonella Enteritidis and Campylobacter jejuni in poultry manure by rearing of Musca domestica fly larvae
}

\author{
S. Nordentoft ${ }^{1 *}$, C. Fischer ${ }^{2}$, L. Bjerrum ${ }^{2}$, L.H. Heckmann ${ }^{2}$ and B. Hald ${ }^{1}$ \\ ${ }^{1}$ National Food Institute, Technical University of Denmark, Bygning 202, 2800 Lyngby, Denmark; ${ }^{2}$ Danish Technological \\ Institute, Kongsvang Allé 29, 8000 Aarhus C, Denmark; snni@food.dtu.dk
}

Received: 30 November 2016 / Accepted: 21 February 2017

(C) 2017 Wageningen Academic Publishers

OPEN ACCESS (1) (1)(2) RESEARCH ARTICLE

\begin{abstract}
A major barrier for using animal waste as substrate for production of insects for feed or food is the concern for safety of the end products. In this study we investigated how rearing of fly larvae of Musca domestica in poultry manure influenced the counts of three pathogenic test strains (Escherichia coli, Salmonella Enteritidis and Campylobacter jejuni) and investigated whether these were transferred from manure to larvae, pupae or adults flies. We monitored quantitative microbiological changes over a study period of seven days. We showed that the decay in the numbers of E. coli, S. Enteritidis, and C. jejuni was faster in manure with rearing of fly larvae than in manure without larvae; an $8 \log _{10}$ reduction of all three test bacteria was observed within four days in manure with larvae; compared to manure without larvae where a 1 to $2 \log _{10}$ was observed. We found no sign of propagation of the pathogens in the larvae gut. All test strains were detectable in low numbers at day 4 in the larvae gut but only C. jejuni survived until day 7. In the pupae, only S. Enteritidis was detectable at day 3, and no test strains were found later than day 3 . None of the test strain was isolated from adult flies. The total aerobic bacterial count remained at a high level throughout the study both in manure, in larvae and in pupae. In conclusion, our results showed that elimination of the pathogens from the manure was accelerated by larvae rearing, but were still detectable at low number in the larvae gut until end of the larvae stage. This study provides data for evaluation of feed safety of fly larvae reared on animal waste. Furthermore suggests a potential use for reduction of these pathogens in manure.
\end{abstract}

Keywords: feed safety, insects, microbial pathogens, manure microbiology, larvae composting

\section{Introduction}

The growing world population emphasises the need to enhance food production in the future (Alexandratos and Bruinsma, 2012). Specifically, providing enough animal protein sources for food and feed is a major challenge for generations to come (Vantomme, 2015). In many developed countries, large parts of arable land is already utilised (Alexandratos and Bruinsma, 2012) consequently, new and sustainable ways of producing protein from yet inaccessible resources are demanded. One opportunity is to improve the recycling of organic waste from livestock production into highly valuable fertiliser and feed components. Livestock production generates large amounts of manure, which can be used as fertiliser in agri- and horticulture. However, intensive livestock production is frequently located on farms which do not have enough land for proper utilisation of the manure, and this practice may lead to pollution of land, crops, water, and streams with phosphorous and nitrogen (Westerman and Bicudo, 2005) and/or zoonotic bacteria (Hrudey et al., 2002). Composting is one way to convert manure into a product which is easier to handle, but the process is time consuming (Westerman and Bicudo, 2005); hence, methods alternative to composting are needed. A potential method is to let insects forage on the manure and then harvest the insects as a method of nutrient extraction. By doing so the composting process is highly accelerated, while at the same time producing a protein-rich insect biomass; a comprehensive review on using insects for waste treatment is given by Cičková et al. (2014).

In nature, many insect species are specialised in degrading organic matter as a part of their life cycle, and by selecting appropriate species, animal waste may be converted into 
a more stable fertiliser product and the harvested insects can be used as a highly nutritious feed for livestock such as poultry or fish (Veldkamp and Bosch, 2015; Widjastuti et al., 2014), which are insectivorous in nature. Insects from the order Diptera are well known for their ability to convert manure, and the common housefly (Musca domestica) (Calvert, 1979; Miller et al., 1974) and the black soldier fly (BSF) (Hermetia illucens) (Sheppard et al., 1995) have been proposed as excellent candidates. However, BSF is not a native species in many countries with temperate climate, and hence it is uncertain if national authorities will allow use of this (and other) non-native insect in largescale production. In contrast, $M$. domestica, one of the most ubiquitous insects in the world, is able to live in most climate zones (Thomas and Jespersen, 1994) facilitating exploitation of this species.

In the 1970s Miller et al. (1974) investigated the conversion of poultry manure by $M$. domestica larvae, and observed a reduction of the initial weight by half, turning the manure into a dry, odourless and granular compound. The $M$. domestica larvae themselves have been shown to be very efficient in converting organic material into high-value protein, and studies have suggested that larvae may be used as processed feed for poultry (Calvert et al., 1969; Zuidhof et al., 2003) and fish (Madu and Ufodike, 2003) where it may replace or supplement fish meal. However, the cost of collecting, transporting, rearing and later processing the insects may exceed the value of the protein itself. Therefore, less laborious ways to rear the larvae are needed. One way is to produce the larvae locally on farms and use the insects unprocessed as feed for fish and poultry. An additional benefit from feeding with fresh insects may be an improvement of animal welfare, health and performance by stimulating a more natural foraging behaviour. However, when rearing larvae in fresh animal manure there is a risk that enteric pathogenic microorganisms, if present, may colonise the larvae. Consequently, these pathogens could potentially cause disease in livestock when used as feed or humans if it enters food production. Early studies have shown that the adult fly may be able to transmit a whole variety of pathogenic microorganisms (Greenberg and Klowden, 1972). Whether these microorganisms are retained from the larval stages, or if flies become contaminated as adults, is not fully understood. Studies on the BSF larvae show a remarkable reduction of Salmonella Enteritidis and Escherichia coli when reared in artificially contaminated manure (Erickson et al., 2004; Lalander et al., 2013), indicating that these bacteria may be partly inactivated during the bioconversion process.

The major challenges for future generations call for novel and innovative solutions in relation to provide enough protein for livestock production and to handle environmental pollution caused by the livestock itself. There is great potential in growing fly larvae on animal waste to recycle protein and to handle animal waste from livestock production. However, feed legislation in some parts of the world constitutes a barrier for integration of insects reared on animal waste/manure in livestock feed; and rightfully so as unwanted contaminants may end up in human food. In Europe faeces is included in the list of prohibited feed materials in regulation (EC) No. 767/2009 (EC, 2009). Before any ban can be lifted, feed safety issues have to be dealt with. Insects are known carriers of zoonotic enteric pathogens found animal waste, but to what extend these pathogens could be amplified in manure and transmitted by the larvae is not known. In the present study, we selected three of the major causes of feed or foodborne disease in poultry and humans (E. coli, S. Enteritidis, or C. jejuni) with the aim to investigate the possible transmission from manure to larvae, pupae or adult fly during a rearing cycle of M. domestica.

\section{Material and methods}

\section{Test strains}

Two isolates, S. Enteritidis (9978230) and E. coli (201152-217), from clinical outbreaks in poultry as well as one Campylobacter jejuni isolate (SC181) previously isolated from broilers were used as test strains in this study. The isolates were stored as stock cultures at $-80^{\circ} \mathrm{C}$ in brain heart infusion (BHI) broth (CM1032; Oxoid, Roskilde, Denmark) supplemented with 15\% glycerol (Sigma-Aldrich, Brøndby, Denmark). Resistance to rifampicin was induced in the $S$. Enteritidis and E. coli isolates by two passages on blood agar base plates (CM271; Oxoid) supplemented with 5\% calf blood (SSI Diagnostica, Hillerød, Denmark) and containing $50 \mu \mathrm{g} / \mathrm{ml}$ rifampicin (Sigma-Aldrich). The C. jejuni was used as a wild type isolate without any modification. The $S$. Enteritidis and E. coli were recovered from freezer stocks by culturing on blood agar (CM271; Oxoid) supplemented with $5 \%$ calf blood (BA; SSI Diagnostica) and incubated aerobically at $37^{\circ} \mathrm{C}$ overnight. One colony from each culture was subcultured on blood agar base plates (CM271; Oxoid) without the addition of blood, but with $50 \mu \mathrm{g} / \mathrm{ml}$ rifampicin $\left(\mathrm{BAB}^{\text {rif }}\right.$ ) and cultured overnight at $37^{\circ} \mathrm{C}$. The C. jejuni was subcultured from the stock culture on BA at $37^{\circ} \mathrm{C}$ for $48 \mathrm{~h}$, microaerobically in jars containing a mixture of $6 \% \mathrm{O}_{2}, 7 \% \mathrm{CO}_{2}$ in $\mathrm{N}_{2}$, using the Anoxomat ${ }^{\mathrm{Ts}}$ system (Mart Microbiology B.V, Drachten, the Netherlands). One colony was then subcultured on Abeyta-Hunt-Bark (AHB) agar supplemented with triphenyltetrazolium chloride (Rosenquist et al., 2006), and incubated at $42{ }^{\circ} \mathrm{C}$ for $48 \mathrm{~h}$ microaerobic. Test cultures for spiking the manure were prepared by inoculating one colony from each of the three test strains individually into $300 \mathrm{ml}$ of BHI broth (CM1135; Oxoid). Following incubation at 16 to $18 \mathrm{~h}$ under aerobic conditions (S. Enteritidis and E. coli) at $37^{\circ} \mathrm{C}$ and C. jejuni at $42{ }^{\circ} \mathrm{C}$, microaerobic, all broth cultures were harvested by centrifugation $\left(4,000 \times g, 20 \mathrm{~min}, 4^{\circ} \mathrm{C}\right)$ and the pellets were 
resuspended in $60 \mathrm{ml}$ of $0.9 \% \mathrm{NaCl}$, normal saline (NS). From each suspension, $1 \mathrm{ml}$ was sampled for enumeration by tenfold diluting and plating $100 \mu \mathrm{l}$ on agar, $\mathrm{BAB}^{\text {rif }}(S$. Enteritidis and E. coli) or AHB (C. jejuni).

\section{Preparing the spiked manure}

One large batch of fresh poultry manure without bedding straw $(30 \mathrm{~kg}$ ) was obtained from a local organic egg producing farm. To ensure that the manure did not contain rifampicin-resistant bacteria, a sample was tested

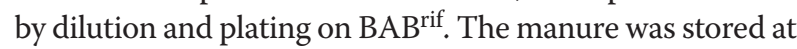
$-20{ }^{\circ} \mathrm{C}$ to kill live insects and eggs. After thawing, $85 \mathrm{~g}$ were weighed into $520 \mathrm{ml}$ plastic cups (Joni, Hounisen, Aarhus, Denmark) and $15 \mathrm{ml}$ of the resuspended test cultures were added to individual cups and thoroughly mixed into the manure achieving a final dry matter (DM) of $30 \%$ and a concentration of the test organisms of approximately $10^{9}$ $\mathrm{cfu} / \mathrm{g}$ manure. The DM of the manure was measured prior to each experiment by incubation of approximately $25 \mathrm{~g}$ manure in an incubator oven at $105^{\circ} \mathrm{C}$ for $24 \mathrm{~h}$. The DM was then calculated based on the weight difference before and after drying. During the experiments, $10 \mathrm{~g}$ manure was sampled daily from one of the control cups in each series and tested for DM content. All cups were tested at the end of the experiment. The $\mathrm{pH}$ in the manure was measured by applying $10 \mu \mathrm{l}$ of the $10^{-1}$ dilution from each manure cup on $\mathrm{pH}$ indicator strips (Hounisen).

\section{Rearing of larvae}

A culture of the common housefly ( $M$. domestica) was established by catching approximately 1000 flies on a local pig farm. The flies were held in cages (Bugdorm-1; MegaView Science Co. Ltd., Taichung, Taiwan) in a climate cabinet (KBWF720; Binder GmbH, Tuttlingen, Germany) at $25{ }^{\circ} \mathrm{C}$, at a relative humidity $(\mathrm{RH})$ of $60 \%$, with a $12: 12$ $\mathrm{h}$ light regime. Flies were provided with sugar and dried skimmed milk (1:3) and water ad libitum. 1-day-old eggs were collected from the adult fly culture and transferred to an artificial hatching medium (a mixture of wheat bran, alfalfa meal, malt and dried yeast) for hatching, as described by Skovgård et al. (2011). The larva cultures were also maintained in the climate chamber at $25^{\circ} \mathrm{C}, \mathrm{RH} 60 \%$. Larvae used in the experiments were harvested from the hatching medium after 3 days, counted and transferred directly to the manure.

\section{Experimental setup}

The basic study design comprised one experimental series per test strains. Each series consisted of three replicate cups with manure (100 g, DM 30\%) that on day 0 post infection received each 200 (manually counted) 3-day old fly larvae, and three replicate cups with manure without larvae that served as controls. The basic study design was repeated twice. Manure cups were sampled until day 7, and no additional manure was supplemented during incubation as it should represent one composting cycle. Figure 1 gives an overview of the course of one series. The cups were covered with filter paper secured with a rubber band and incubated at $25^{\circ} \mathrm{C}, \mathrm{RH} 60 \%$ in an ECSO climate chamber (Holm-Halby, Brøndby, Denmark). Samples of manure $(0.5 \mathrm{~g})$ from all cups were obtained at day $0,1,2,3,4$ and 7 post inoculation, from larvae (batches of 10) at day 0 , $1,2,3,4$ and 7 post inoculation, from pupae (batches of 10) at day 3, 4 and 7 post inoculation, and from adult flies (batches of 10) at day 15 and 23 post inoculation. In total, the experiments comprised analyses of 108 samples from manure with larvae rearing, 108 samples from manure without larvae, 108 batches of larvae, 54 batches of pupae and 6 batches of adult flies.

\section{Enumeration of test strains and total viable counts}

\section{In manure}

With $24 \mathrm{~h}$ intervals, the number of test bacteria was measured by enumerating cfu on selective agar media. Due to the induced rifampicin resistance in $S$. Enteritidis and $E$. coli, both isolates could be enumerated directly by culturing on $\mathrm{BAB}^{\text {rif }}$, as no background flora emerged on these selective plates. The $C$. jejuni could be enumerated on the highly selective and chromogenic AHB agar instead. Total viable count (TVC) was measured by plating on BAB without rifampicin. For enumeration, approximately $0.5 \mathrm{~g}$ manure was collected from each cup and tenfold dilutions series in NS was made. $100 \mu \mathrm{l}$ from each dilution were spread on agar plates. To increase specificity, all plates containing rifampicin were incubated at $42{ }^{\circ} \mathrm{C}$ for $24 \mathrm{~h}$ under aerobic conditions. AHB plates were incubated microaerobically at $42{ }^{\circ} \mathrm{C}$ for $48 \mathrm{~h}$, and the TVC plates at $37^{\circ} \mathrm{C}$ for $24 \mathrm{~h}$. Only plates containing $<300$ colonies were counted.

\section{In larvae}

Parallel to collecting samples from the spiked manure, 10 larvae from each of the three manure cups with larvae were collected for quantitative measurements of internal bacteria in the larvae. The larvae were transferred to a 1.7-ml tube (Eppendorf, Hamburg, Germany) and external bacteria were killed by washing in $1 \mathrm{ml}$ of $0.26 \%$ sodium hypochlorite (Sigma-Aldrich) solution for 4 min., repeated 3 times and then washed 5 times in $1 \mathrm{ml}$ of NS. Following the final wash, all NS was removed with a pipette, the larvae weighed, and finally homogenised in the tube by using a micro pestle (Eppendorf), and finally diluted 1:10 w/v in NS. Bacterial culture, enumeration and TVC were performed as described for manure. 


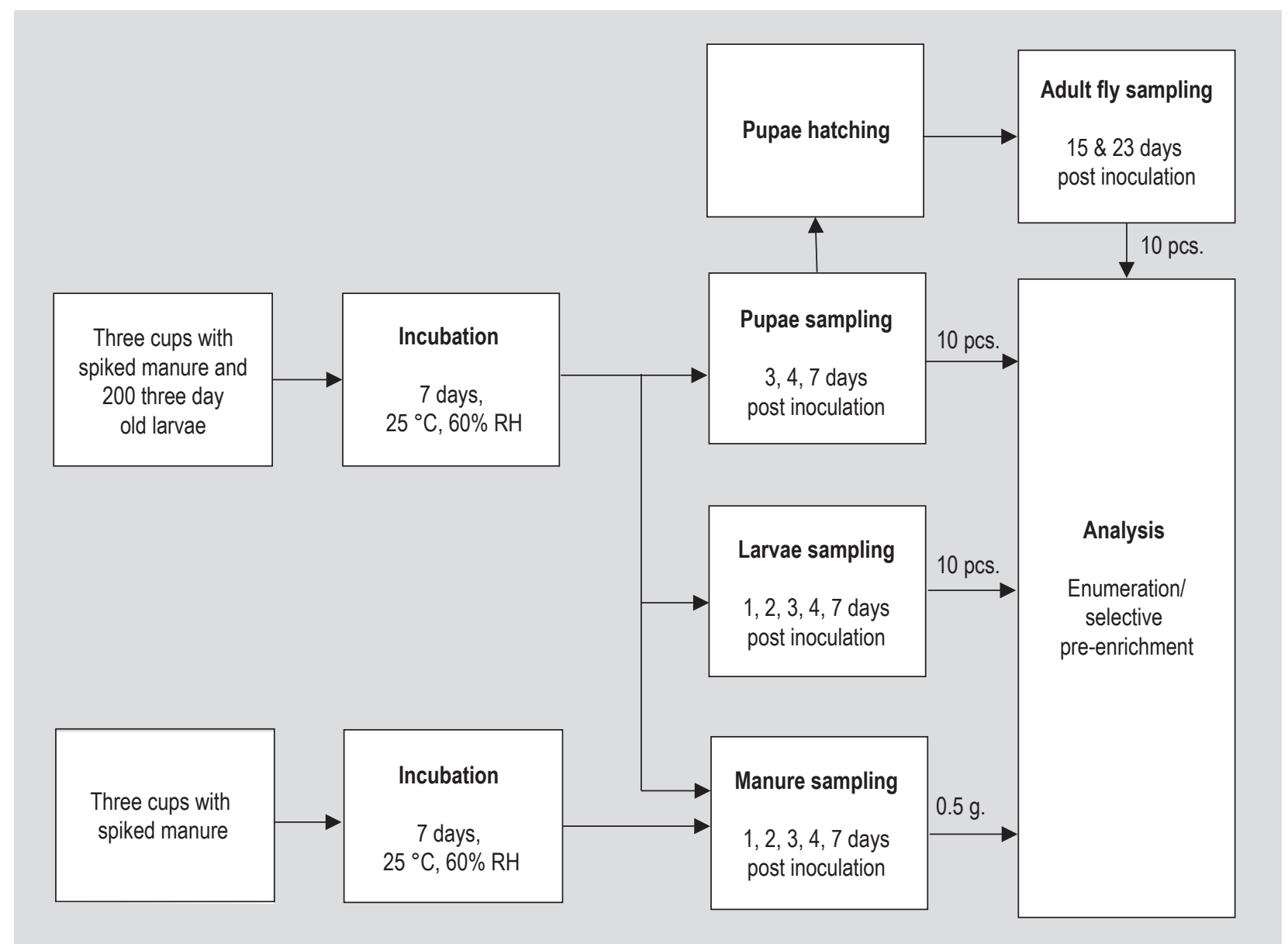

Figure 1. Flow diagram of the experimental setup. The diagram covers one experimental series of sampling of one test strain ( $\mathrm{RH}=$ relative humidity).

\section{In pupae}

During the experiment the larvae pupated. The first pupae emerged on day 3. All pupae available on day 3, 4 and 7 post inoculation were harvested from individual cups, transferred to corresponding petri dishes and stored in the climate chamber together with the manure test cups. On day 8 post inoculation, a batch of 10 pupae from each petri dish were transferred to 1.7-ml tubes (Eppendorf) to be disinfected and homogenised. Bacterial culture and enumeration were performed as described for manure. Pupae in excess were transferred to a net cage for emerging into adults.

\section{Detection of test strains by pre-enrichment of samples from manure, larvae and pupae.}

When the cfu counts of the test bacteria was expected to be at or below detection level (100 cfu/g manure), a pre-enrichment step was included. Samples tested for $S$. Enteritidis were pre-enriched by transferring $1 \mathrm{ml}$ of a $10^{-1}$ dilution into $9 \mathrm{ml}$ of buffered peptone water (CM1049;
Oxoid), incubated aerobically at $37^{\circ} \mathrm{C}$ for $18 \mathrm{~h}$. Then 3 drops (50 $\mu \mathrm{l}$ each) were applied in a triangle on modified semisolid Rappaport-Vassiliadis agar (CM0910, SR0161; Oxoid) and incubated at $42{ }^{\circ} \mathrm{C}$ for $48 \mathrm{~h}$. Using a 1- $\mu$ l loop needle, material from the border of opaque swarming zones on the semisolid plates were streaked on $\mathrm{BAB}^{\text {rif }}$ plates, and incubated at $42{ }^{\circ} \mathrm{C}$ for $24 \mathrm{~h}$. For E. coli samples, preenrichment were performed by transferring $1 \mathrm{ml}$ of a $10^{-1}$ dilution in $9 \mathrm{ml}$ of EC broth (CM0853; Oxoid), followed by incubation at $42{ }^{\circ} \mathrm{C}$ for $24 \mathrm{~h} .10 \mu \mathrm{l}$ of this culture was then spread on $\mathrm{BAB}^{\text {rif }}$ and incubated at $42{ }^{\circ} \mathrm{C}$ for $24 \mathrm{~h}$. Pre-enrichment of $C$. jejuni was performed by adding $1 \mathrm{ml}$ of a $10^{-1}$ dilution into to $9 \mathrm{ml}$ of Bolton broth (CM0983, SR0048, SR0183; Oxoid), and then incubated at $42{ }^{\circ} \mathrm{C}$ for $24 \mathrm{~h}$ microaerobically. $10 \mu \mathrm{l}$ was then streaked on an AHB agar plate and incubated at $42^{\circ} \mathrm{C}$ for $48 \mathrm{~h}$. Growth of typical dark red colonies was considered as $C$. jejuni. Due to less sample material from larvae and pupae, pre-enriched was performed by transferring the remaining amount (app 0.5-1.0 ml) of the $10^{-1}$ dilution of the diluted homogenised larvae into $9 \mathrm{ml}$ of the pre-enrichment buffers. 


\section{Detection of test strains in adult flies}

On day 8 post inoculation, a net cage with collected pupae was placed in the climate cabinet $\left(25^{\circ} \mathrm{C}, \mathrm{RH} 60 \%\right.$, supplemented with 12:12 h light:dark ratio) and adult flies developed during a few days. The flies were fed a diet of sugar, dried skimmed milk (1:3) and water ad libitum. Adult flies and filter paper from the water supply were tested for the test strains by pre-enrichment culture on day 15 and 23 post inoculation. 10 flies were captured in a batch in a $50-\mathrm{ml}$ tube and placed at $-18{ }^{\circ} \mathrm{C}$ for $5 \mathrm{~min}$. The anesthetized flies were then mixed with $1 \mathrm{ml}$ of the relevant pre-enrichment broth in a mortar and homogenised. This suspension was transferred to $9 \mathrm{ml}$ of the pre-enrichment broth and incubated as previously described. The filter paper was analysed by submerging the paper in $9 \mathrm{ml}$ of pre-enrichment broth and incubated according to the strain to be detected.

\section{Data and statistical analyses}

Bacterial plate counts were calculated and adjusted according to the sample weight. All counts were transformed to $\log _{10}$ and the mean and standard deviations calculated using Microsoft Excel (Microsoft, Redmond, WA, USA). The two datasets were normalised in order to include them in the same statistical analysis. All data was confirmed as normally distributed assessed with the Shapiro-Wilks' test and visual assessment using qqnorm in $\mathrm{R}$ (version 3.3.2; https://www.r-project.org/). Differences in mean values of relevant samples were computed in GraphPad Prism (version 6.0.3; GraphPad Software, Inc., La Jolla, CA, USA) using a two-way ANOVA with a Sidak post-hoc analysis. In all the statistical tests, the level for significance was set at $5 \%(P<0.05)$.

\section{Results}

\section{Larvae development in the manure}

The 3-day old larvae that were seeded to the manure continued their development, and the first pupae emerged on day three post inoculation. Within the following four days (day 4 to day 7), the majority of larvae had pupated, leaving a few non-pupated larvae at the termination of manure incubation on day seven.

\section{Changes in microbiology of the manure}

Quantitative culture data of the test strains from the manure cups are presented in Figure 2 and the TVC count in Figure 3 . The counts of test strains on day 0 in all manure cups were between $10^{8}$ and $10^{9} \mathrm{cfu} / \mathrm{g}$. In cups with larvae, these were reduced to below the detection limit by direct culture $\left(10^{2} \mathrm{cfu} / \mathrm{g}\right)$ within the first four days, but could be detected by pre-enrichment in 2 out of 6 cups (E. coli) and in 1 out

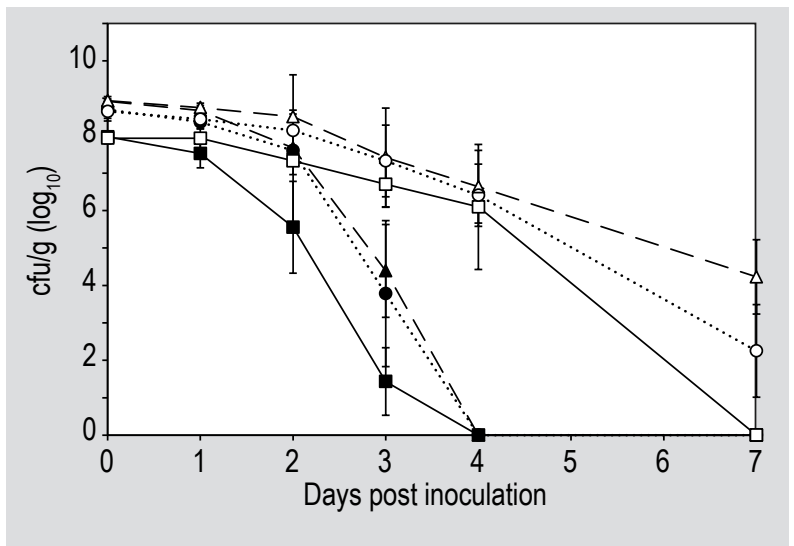

Figure 2. Colony forming unit (cfu) counts of poultry manure with Musca domestica fly larvae and spiked with three test bacteria, Escherichia coli $(\bullet)$, Salmonella Enteritidis ( $\mathbf{\Delta}$ ) or Campylobacter jejuni (ם), and in manure without larvae, $E$. coli ( () , S. Enteritidis $(\Delta)$ and $C$. jejuni $(\square)$. Curve and error bars represent mean and standard deviations based on six replicates.

of 6 cups ( $S$. Enteritidis) on day 4, whereas all samples were negative on day 7. In manure without larvae a reduction of the test strains was also observed, but all cups were still positive by direct culture on 4 day, and $S$. Enteritidis also on day 7. The two other strains could only be detected by enrichment on day 7. Overall, the two-way ANOVA showed a significant interaction $(P<0.05)$ between time and reduction in bacterial counts for both manure with and without larvae. There was a significant $(P<0.05)$ higher reduction of $C$. jejuni and $S$. Enteritidis at days 1 and 2 in manure with larvae when comparing to the respective bacterial counts on the same day without larvae. Although not significantly different, E. coli was reduced in a similar pattern with larvae. Hence, the reduction rate of the test

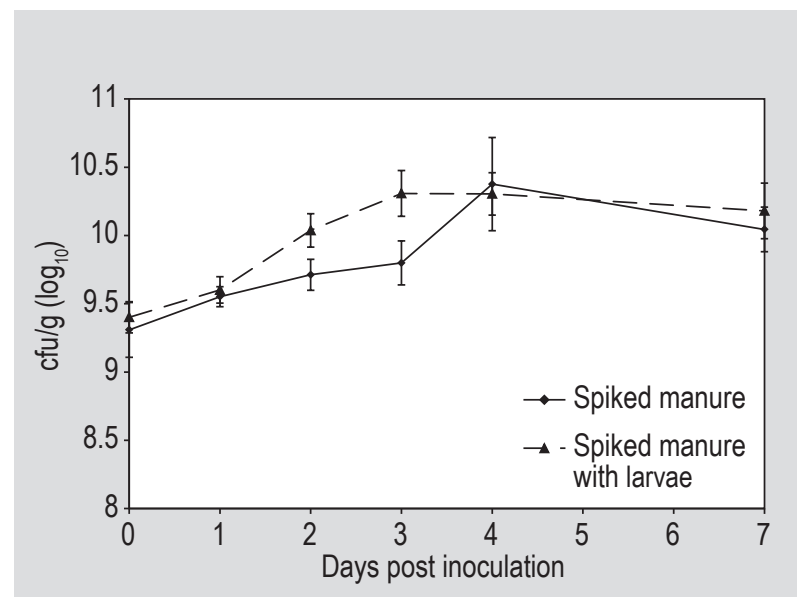

Figure 3. Total viable counts of manure spiked with one of the three test bacteria with and without the addition of fly larvae (Musca domestica). Curve and error bars represent mean and standard deviations based on data from 18 replicates. 
strains was quicker in manure with larvae than without larvae (Figure 2). The total aerobic microbial flora (TVC) in the manure increased 1-log during the 7 days of incubation in all cups following the same overall trend in manure with and without larvae (Figure 3).

\section{The microbiology inside the larvae, pupae and adult fly}

\section{Larvae}

All larvae tested negative for the three test strains prior to inoculation (day 0 ). On day 1 , test strains could be cultured in high numbers from the interior of the larvae (Figure 4). Comparable to the findings in the manure (Figure 2), a more than $6 \log$ reduction was observed inside the larvae on day 4. No test strains could be detected by direct culture on day 4 , but $C$. jejuni could be recovered by pre-enrichment in one experiment (3 cups). In contrast to the rapid decay of test strains from the inside of the larvae, the TVC in larvae stayed at a level around $10^{9}$ to $10^{10} \mathrm{cfu} / \mathrm{g}$ throughout the experiment (Figure 4).

\section{Pupae}

The first pupae emerged at day 3. At this day, $S$. Enteritidis was recovered by pre-enrichment culture in 2 out of 4 direct-culture negative samples, but all other or later pupae samples were negative for test strains by any tests. The TVC in the pupae reached $10^{8}$ to $10^{10} / \mathrm{g}$ pupae.

\section{Adult fly}

Pupae from the same experiment were pooled and placed in a cage for eclosure. It was not possible to recover any of the test strains in any of the adult flies at day 15 and 23 or from culturing the filter paper placed in the water supply neither by direct-culture nor by pre-enrichment culture methods.

\section{Physical changes in the manure during composting}

During the seven day long composting process the mean DM content rose from $30 \%( \pm 0.7)$ to $40.5 \%( \pm 3.9)$ in cups with larvae and to $39.7 \%( \pm 1.9)$ in control cups. An increase in $\mathrm{pH}$ from 7 to 8 was observed in both test and control cups.

\section{Discussion}

E. coli, S. Enteritidis and C. jejuni initially became part of the microbial flora in the gut of the larvae reared in the spiked manure (Figure 4), with concentrations comparable to that in the manure (Figure 2). The concentration in the larvae never exceeded the number in the manure, indicating that the test bacteria did not multiply inside the larvae. Contrary, a noteworthy fast elimination with an overall similar inactivation rate of the test strains was observed

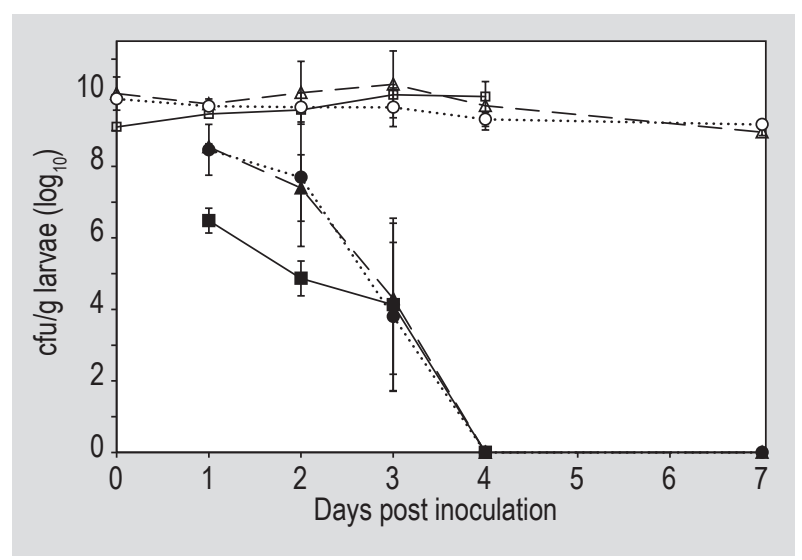

Figure 4. Colony forming unit (cfu) counts of the gut of fly larvae (Musca domestica) reared in poultry manure spiked with Escherichia coli $(\bullet)$, Salmonella Enteritidis $(\boldsymbol{\Delta})$ or Campylobacter jejuni $(\square)$ and total viable counts in the gut of the larvae in the manure spiked with E. coli (०), S. Enteritidis $(\Delta)$ or C. jejuni $(\square)$. Curve and error bars represent mean and standard deviation based on data from six replicates.

both in the manure containing larvae (Figure 2) and in the larvae gut (Figure 4). A reduction was observed in manure samples without larvae as well, however with a lower inactivation rate, and three test bacteria could still be cultured from the manure on day 7. An explanation for the observed self-sanitation in manure without larvae could be that the test strains are not part of a natural microbiota and were inactivated by ammonia released from degrading manure. Fidjeland et al. (2013) observed a fast self-sanitation of faecal sludge contaminated with $S$. Typhimurium, and found that this inactivation was depended on the concentration of ammonia. The balance between ammonia and ammonium is highly influenced by temperature or $\mathrm{pH}$ above 8 (Emerson et al., 1975), and as we observed only minor increase from $\mathrm{pH} 7$ to 8 in both controls and test vials, this may explain the relatively slow self-sanitation that was observed in our controls. So, the rearing of $M$. domestica larvae seemed to accelerate the decay of pathogens in the manure in other ways. In a previous study, (Greenberg and Klowden, 1972) also showed the capability of $M$. domestica larvae to reduce certain bacteria in manure as the larvae were found to eliminate S. Typhi and Shigella flexneri, but not S. Paratypi B. Other fly species, such as the BSF, have shown similar capabilities of reducing pathogenic bacteria from the rearing medium. By culturing BSF larvae in spiked manure, $S$. Enteritidis and $E$. coli were reduced in poultry, pig and cow manure (Erickson et al., 2004; Liu et al., 2008), and S. Typhimurium in human faeces (Lalander et al., 2013).

Changes in manure texture during the accelerated composting may also have contributed to dynamical changes in the microbial flora as the manure was converted from a light-brown and clayey material to a dark and porous 
material. This might improve conditions for the aerobic flora in general as well as contribute to the reduction of the three test strains. During the incubation a one log increase in TVC was observed in all cups (Figure 3), but it is likely a reflection of the observed increase in DM which increased over time. Together this suggests that the aerobic microbiota in the manure is modified during the composting process by the larvae, where some bacteria are assimilated by the larvae, while other bacterial species propagate inside the larval gut. As TVC only reflects the counts / weight of aerobic bacteria it is not possible to tell whether an overall reduction of bacteria has happened or how anaerobic counts are affected by the larvae. Future studies are required to clarify this and identify which other bacteria that seems to be favoured by the larva composting process.

One explanation for the observed elimination of the test strains from the larvae gut could be that microorganisms, including bacteria, have been reported to be an important food source for $M$. domestica during larval development (Schmidtmann and Martin, 1992; Zurek et al., 2000). In those studies, it was shown that some defined pure cultures of specific bacteria species supported the development of the larvae while other strains failed. This may indicate that specific groups of bacteria are important for the development of larvae, and the tropism for specific strains may also explain why only fresh manure is capable of sustaining growth of fly larvae (Beard and Sands, 1973). The breakdown of bacteria in the larvae gut seems to be a selective process because TVC was maintained at a constant high level both in manure and inside larvae throughout the study. The ability of $M$. domestica, as well as other members of Diptera cyclorrhapha, to digest complex structures as bacteria may relate to a highly active gut system. The gut is characterised by a central mid-mid gut with low $\mathrm{pH}$ flanked by a fore-mid gut and a hind-mid gut with neutral pH (Greenberg and Klowden, 1972). Several different types of digestive enzymes have been demonstrated in the mid gut (Lemos and Walter, 1991), which may explain the ability to digest bacteria. Especially a homologue lysozyme enzyme working at a low $\mathrm{pH}$ which is capable of breaking down the peptidoglycan layer in the cell wall of Gram-positive bacteria may be involved (Lemos et al., 1993). However, a number of other enzymes have also been isolated from the M. domestica mid gut (Padilha et al., 2009). Another explanation for the reduction inside the larvae could be bacterial antagonisms exerted by the microbial flora from the manure, because no reduction was reported when gnotobiotic larvae were reared in media without competing microorganisms (Greenberg and Klowden, 1972); however, autoclaving the manure did not affect the elimination in another study (Erickson et al., 2004).

To prevent bias from temperature-mediated killing of the test bacteria, we used a fixed manure temperature of $25{ }^{\circ} \mathrm{C}$ established by incubating small cups in a controlled environment at a fixed incubator temperature. In production-sized units (considerably larger than our experimental cups), the reducing effect of temperature on certain bacteria may likely be larger than indicated in our study as the natural composting process will generate heat and increase the temperature in the manure to 30$50{ }^{\circ} \mathrm{C}$. By the increased temperature, a faster killing of bacteria will be achieved which suggests that $M$. domestica larvae may eliminate pathogens at a higher speed at higher temperatures (within their biological temperature optimum). When Erickson (Erickson et al., 2004) tested different rearing temperatures of BSF larvae, they observed the highest reduction of pathogens at $32{ }^{\circ} \mathrm{C}$.

The concern for the feed safety of insect products produced on animal waste is due to the fact that adult stages of $M$. domestica are able to house a whole variety of pathogenic microorganisms (Greenberg and Klowden, 1972) and are well known vectors in the spread of Salmonella spp. and C. jejuni to livestock animals (Bahrndorff et al., 2013; Holt et al., 2007). It is however unclear if presence of pathogens in the adult fly can be due to transmission from the rearing media or only by uptake later on as adults, where carriage has been shown to be short-termed for $S$. Enteritidis and C. jejuni (Greenberg et al., 1970; Holt et al., 2007; Skovgård et al., 2011). In our study, most larvae samples became negative between day 4 and 7 . We further note that only the first emerging pupae on day 3 were positive $S$. Enteritidis, and were not able to detect any E. coli, S. Enteritidis, or $C$. jejuni in later pupae or in the adult flies. This showed that the pathogens were not transferred from contaminated manure to pupae or adult flies. Concerning feed safety of larvae to be part of a feed product, our results showed that although the fly larvae clearly showed an ability to eliminate the three pathogens they may still be present in low numbers in the early larva stages $M$. domestica. Therefore it is urgent to integrate disinfection or processing step in the production protocol before the end product is released.

There is great potential in growing fly larvae on animal waste to use the larvae for animal feed. However, traditions and legislation still constitute a barrier for integration of insects raised on animal waste/manure as animal feed. Before any ban can be lifted, feed safety issues have to be dealt with, especially with regard to microbiology and accumulation of chemical residues. Our study contributed with data within feed safety of fly larvae products of M. domestica and furthermore suggests a potential for utilisation of the larvae to control of pathogenic bacteria in manure.

In conclusion, our study showed that rearing of live $M$. domestica larvae in manure accelerated the reduction of E. coli, S. Enteritidis and C. jejuni during the composting process of the manure. Furthermore, that diminutive 
amount of the test strains could still be present inside larvae at early stage, but no propagation of the bacteria or transmission to the adult fly were observed. Nevertheless, to produce a larvae product free of any harmful live microorganism, a disinfection treatment will have to be included before application of the end-product. Heat treatment is an obvious solution, but further research is needed to show the efficacy.

\section{Acknowledgements}

The work was funded by The Danish AgriFish Agency, Ministry of Food, Agriculture and Fisheries, gran number 3405-10-OP-00165. The project BioConval is part of the Organic RDD programme, which is coordinated by International Centre for Research in Organic Food Systems, ICROFS. We thank Søs Siem for excellent technical work.

\section{References}

Alexandratos, N. and Bruinsma, J., 2012. World agriculture towards 2030/2050: the 2012 ESA working paper no. 12-03. FAO, Rome, Italy, 154 pp. Available at: http://tinyurl.com/pn4y8rc.

Bahrndorff, S., Rangstrup-Christensen, L., Nordentoft, S. and Hald, B., 2013. Foodborne disease prevention and broiler chickens with reduced Campylobacter infection. Emerging Infectious Diseases 19: 425-430.

Beard, R.L. and Sands, D.C., 1973. Factors affecting degradation of poultry manure by flies. Environmental Entomology Entomological Society of America 2: 801-806.

Calvert, C., 1979. Use of animal excreta for microbial and insect protein synthesis. Journal of Animal Science 48: 178-192.

Calvert, C.C., Martin, R.D. and Morgan, N.O., 1969. House fly pupae as food for poultry. Journal of Economic Entomology 62: 938-939.

Cičková, H., Newton, G.L., Lacy, R.C. and Kozánek, M., 2014. The use of fly larvae for organic waste treatment. Waste Management 35: 68-80.

Emerson, K., Russo, R.C., Lund, R.E. and Thurston, R.V., 1975. Aqueous ammonia equilibrium calculations: effect of $\mathrm{pH}$ and temperature. Journal of the Fisheries Research Board of Canada 32: 2379-2383.

Erickson, M.C., Islam, M., Sheppard, C., Liao, J. and Doyle, M.P., 2004. Reduction of Escherichia coli O157:H7 and Salmonella enterica serovar Enteritidis in chicken manure by larvae of the black soldier fly. Journal of Food Protection 67: 685-690.

European Commission (EC), 2009. Regulation (EC) No 767/2009 of the European parliament and of the council of 13 July 2009 on the placing on the market and use of feed, amending European Parliament and Council Regulation (EC) No 1831/2003 and repealing Council Directive 79/373/EEC, Commission Directive 80/511/EEC, Council Directives 82/471/EEC, 83/228/EEC, 93/74/ EEC, 93/113/EC and 96/25/EC and Commission Decision 2004/217/ EC. Official Journal of the European Union L 229: 1-28.

Fidjeland, J., Magri, M.E., Kan Jönsson, H., Albihn, A. and Vinnerå S.B., 2013. The potential for self-sanitisation of faecal sludge by intrinsic ammonia. Water Research 47: 6014-6023.
Greenberg, B. and Klowden, M., 1972. Enteric bacterial interactions in insects. The American Journal of Clinical Nutrition 25: 1459-1466.

Greenberg, B., Kowalski, J. and Klowden, M., 1970. Factors affecting the transmission of Salmonella by flies: natural resistance to colonization and bacterial interference. Infection and Immunity 2: 800-809.

Holt, P.S., Geden, C.J., Moore, R.W. and Gast, R.K., 2007. Isolation of Salmonella enterica serovar Enteritidis from houseflies (Musca domestica) found in rooms containing Salmonella serovar Enteritidis-challenged hens. Applied and Environmental Microbiology 73: 6030-6035.

Hrudey, E.J., Huck, P., Hrudey, S.E., Payment, P. and Gillham, R.W., 2002. Walkerton: lessons learned in comparison with waterborne outbreaks in the developed world. Journal of Environmental Engineering and Science 1: 397-407.

Lalander, C., Diener, S. and Magri, M., 2013. Faecal sludge management with the larvae of the black soldier fly (Hermetia illucens) - from a hygiene aspect. Science of the Total Environment 458-460: 312-318.

Lemos, A.J.A. and Walter, R., 1991. Digestion of bacteria and the role of midgut lysozyme in some insect larvae. Comparative Biochemistry and Physiology 100B: 265-268.

Lemos, F.J. a., Ribeiro, A.F. and Terra, W.R., 1993. A bacteriadigesting midgut-lysozyme from Musca domestica (Diptera) larvae. Purification, properties and secretory mechanism. Insect Biochemistry and Molecular Biology 23: 533-541.

Liu, Q., Tomberlin, J. and Brady, J., 2008. Black soldier fly (Diptera: Stratiomyidae) larvae reduce Escherichia coli in dairy manure. Environmental Entomology 37: 1525-1530.

Madu, C.T. and Ufodike, E.B.C., 2003. Growth and survival of catfish (Clarias anguillaris) juveniles fed live tilapia and maggot as unconventional diets. Journal of Aquatic Sciences Association of Aquatic Sciences in Nigeria 18: 47-52.

Miller, B.F., Teotia, J.S. and Thatcher, T.O., 1974. Digestion of poultry manure by Musca domestica. British Poultry Science 15: 231-234.

Padilha, M.H.P., Pimentel, A.C., Ribeiro, A.F. and Terra, W.R., 2009. Sequence and function of lysosomal and digestive cathepsin D-like proteinases of Musca domestica midgut. Insect Biochemistry and Molecular Biology 39: 782-791.

Rosenquist, H., Sommer, H.M., Nielsen, N.L. and Christensen, B.B., 2006. The effect of slaughter operations on the contamination of chicken carcasses with thermotolerant Campylobacter. International Journal of Food Microbiology 108: 226-232.

Schmidtmann, E.T. and Martin, P.A., 1992. Relationship between selected bacteria and the growth of immature house flies, Musca domestica, in an axenic test system. Journal of Medical Entomology 29: 232-235.

Sheppard, D.C., Thompson, S.A. and Savage, S., 1995. A value added manure management system using the black soldier fly. Bioresource Technology 50: 275-279.

Skovgård, H., Kristensen, K. and Hald, B., 2011. Retention of Campylobacter (Campylobacterales: Campylobacteraceae) in the house fly (Diptera: Muscidae). Journal of Medical Entomology 48: 1202-1209.

Thomas, G. and Jespersen, J.B., 1994. Non-biting Muscidae and control methods. Revue Scientifique et Technique 13: 1159-1173. 
Vantomme, P., 2015. Farming insects as a viable and global source of animal proteins. Atti Accademia Nazionale Italiana di Entomologia 63: 57-63.

Veldkamp, T. and Bosch, G., 2015. Insects: a protein-rich feed ingredient in pig and poultry diets. Animal Frontiers 5: 45-50.

Westerman, P.W. and Bicudo, J.R., 2005. Management considerations for organic waste use in agriculture. Bioresource Technology 96: 215-221.

Widjastuti, T., Wiradimadja, R. and Rusmana, D., 2014. The effect of substitution of fish meal by black soldier fly (Hermetia illucens) maggot meal in the diet on production performance of quail (Coturnix coturnix japonica). Animal Science 57: 125-129.
Zuidhof, M., Molnar, C., Morley, F., Wray, T., Robinson, F., Khan, B., Al-Ani, L. and Goonewardene, L., 2003. Nutritive value of house fly (Musca domestica) larvae as a feed supplement for Turkey poults. Animal Feed Science and Technology 105: 225-230.

Zurek, L., Schal, C. and Watson, D., 2000. Diversity and contribution of the intestinal bacterial community to the development of Musca domestica (Diptera: Muscidae) larvae. Journal of Medical Entomology 37: 924-928. 
